\title{
A Convenient Method of Improving Doctor-patient Communication in Hallux Valgus Surgery: Visual Animations
}

\author{
(D) Alican Barış \\ University of Health Sciences Turkey, İstanbul Training and Research Hospital, Department of Orthopaedics and Traumatology, Istanbul, Turkey
}

\section{Abstract}

Objective: This study aimed to investigate the effects of using visual animation on the informed consent for hallux valgus surgery, patient awareness, and patient satisfaction.

Methods: This study included 42 patients with hallux valgus for whom distal metatarsal osteotomy surgeries were planned. During the informed consent process, the patients were informed verbally and in writing. Their knowledge levels were measured using open-ended questions. An animated video, which included disease findings and steps of the planned surgery, was shown to the patients after 28 days on average. The effects of the visual animation on the knowledge levels of the patients and on the satisfaction levels with the patient-doctor communication were examined. Data were analyzed statistically.

Results: Although the animated video provided information on hallux valgus deformity and distal metatarsal osteotomy, patients expressed a better understanding of surgical complications and other treatment options. Video animation significantly increased the knowledge and satisfaction levels of the patients $(p=0.001 ; p<0.01$, respectively).

Conclusion: Video animations that provide patients with easily accessible, inexpensive, reproducible, permanent, impressive, and understandable audiovisual information about diseases may be applied in obtaining informed consent and in improving patient-doctor communication.

Keywords: Video animation, informed consent, hallux valgus

\section{INTRODUCTION}

Hallux valgus is a common condition and reduces the life quality of the patients. In general, surgery is recommended for patients with moderate or severe deformities and in symptomatic cases (1). Over 100 surgical procedures have been described for hallux valgus surgery (2,3). As no surgical approach has been established as the gold standard for hallux valgus, the surgical complication rate reaches $15 \%$ (4). Patients with hallux valgus are also at risk of postoperative complications; thus, they should be informed correctly and adequately about the treatment.

Surgeons have an ethical and legal obligation to provide patients with adequate information about the risks, benefits, and alternatives of invasive procedures in the surgeon-patient interview and in the informed consent process (5).

In situations where the number of patients per doctor is high, the time allocated for the patient may be limited. However, doctorpatient communication may be affected by the sociocultural beliefs of the patients, use of unfamiliar medical terms, use of foreign language, and illiteracy. To address these difficulties, simple, fast, understandable, and repeatable communication methods are needed to improve doctor-patient communication.

This study aimed to examine the effects of using threedimensional animated videos supported by a tablet PC to explain hallux valgus findings and surgical procedures on the informed consent process and patient satisfaction. 


\section{METHODS}

The study was approved by the Clinical Research Ethics Committee (dated: 15.01.2016, decision no: 757). A total of 42 patients who were diagnosed with hallux valgus between February 2016 and November 2018, who were not relieved of their complaints with conservative treatments, and who were planned for distal metatarsal osteotomy surgery were included in the study after their informed consent forms were received.

The gender, age, educational status, diagnosis, and planned surgery data of the patients were recorded. Patients were informed verbally and in writing about the surgery, surgeryspecific complications, diagnoses, disease findings, stages of the planned surgery, and treatment options other than the planned surgery in the polyclinic conditions. For objective evaluation, six items were prepared for each information (3,6-9). After a verbal and written explanation, patients were asked open-ended questions to determine their knowledge levels (5,10-12). Correct answers to each open-ended question were scored 0-6 points according to the information provided previously. Patients who provided incorrect responses scored 0 , and those with correct answers in all six items were given 6 points.

Patients who received surgery appointments were taken to the orthopedic unit after 28 (15-65) days on average. An animated video that included the findings of the disease and steps of the planned surgery was shown to the patients in the unit (Ankle \& Foot Pro III 3.8.1 and Complete Orthopedic version 1.1.1 3D4 Medical's NOVA3 Technology) through a tablet PC (iPad Wi-Fi 128GB Black; Apple Inc., CA, USA) (Figure 1).

Although explanations were not included in the animated video, explanations were given about other treatment options and surgery-related complications. Patients were asked again with the same open-ended questions to determine their knowledge levels after they have watched the animation. The knowledge level after watching the animation was also scored 0-6 points. Patients scored 0 points if they did not know any of the items asked and 6 points if they knew all of them.

In addition, the satisfaction with the written-oral informed consent form and animated video and informed consent form was scored 0-6 points. Data obtained were compared statistically.

\section{Statistical Analysis}

The Number Cruncher Statistical System 2007 (Kaysville, UT, USA) program was employed for statistical analyses. Wilcoxon signedrank test and descriptive statistical methods (mean, standard deviation, median, frequency, percentage, and minimummaximum values) were employed to compare quantitative data.
In the intragroup comparisons of the study variables, which did not show a normal distribution, the Wilcoxon signed-rank test was employed. The significance level was taken as $p<0.01$ and $\mathrm{p}<0.05$.

\section{RESULTS}

Demographic features of the participants are shown in Table 1. Significant increases were detected in the knowledge level on the disease findings, surgery steps, other treatment options, surgery-related complications, and satisfaction with the use of animation in obtaining informed consent (Table 2) $(p=0.001$; $\mathrm{p}<0.01)$.

\section{DISCUSSION}

This study focused on the effect of using visual animation on the informed consent process in patients with hallux valgus, for whom distal metatarsal osteotomy was planned as treatment. In this study, the use of visual animations increased the knowledge and satisfaction levels of the patients about the topic.

Hallux valgus is more common in women, the function of the foot is disrupted, and patients are anxious about the postoperative appearance of the foot (9). This situation increases the expectation in the hallux valgus surgery, which is already at risk of complications $(9,13)$. Thus, the surgeon must fully inform the patient in a sufficient, accurate, and understandable manner to relieve the patients of their anxiety.

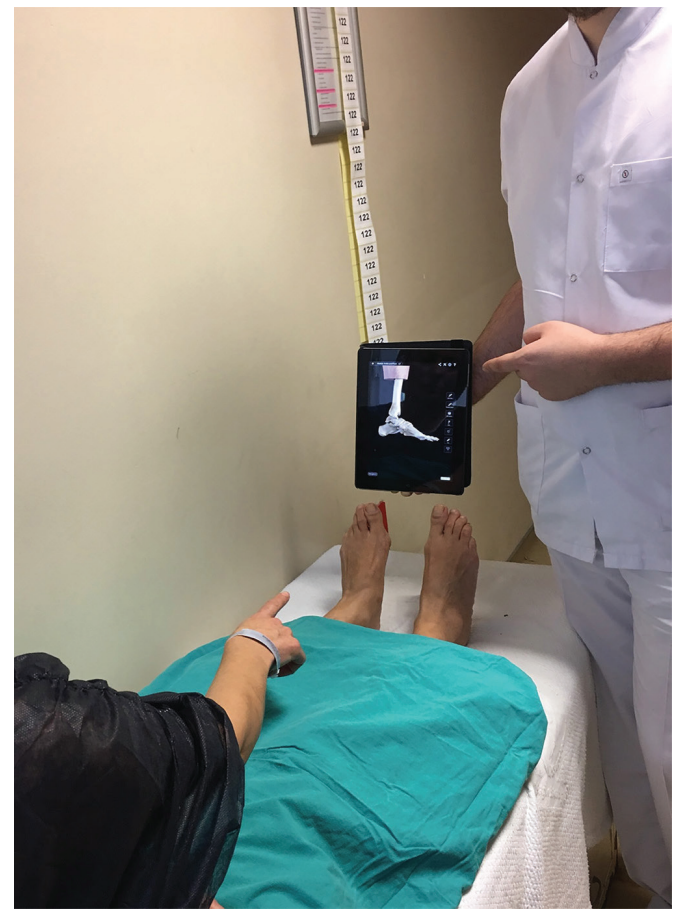

Figure 1. Method of showing visual animations to the patients 
Patients have the right to demand verbal or written explanations of their diagnoses, treatment, benefits and possible risks of surgical treatment, alternative treatment methods, disease progression, and expected outcomes if they reject the treatment (10). However, in current practice, patients cannot receive sufficient information on the surgical procedures from doctors, nurses, and other healthcare staff $(14,15)$. This situation results in doubts, fear, or anxiety in the patients about establishing a relationship with the healthcare staff, and they might approach the surgical process and relevant outcomes with fear $(12,16)$.

The facilitated access to information in parallel with recent technological developments has substantially improved the patient-doctor relationship (17). The true-false information that patients obtained from the internet before consulting with the doctor affects the transfer of information from the doctor to the patients (18). Although patients were passive in the past about their decisions related to their treatments, they have now become more active $(19,20)$. This situation requires that patients receive accurate information about their treatment $(18,21)$.
A study that investigated how much patients were informed before their surgeries reported that nearly one-fourth of these patients were not informed at all, nearly one-fifth did not know their diagnoses, and more than half did not know their surgical procedures. Moreover, $12 \%$ and $14 \%$ of the patients stated that they were not informed of the complications that might occur during and after surgery, respectively. The study emphasized that verbal and written information was insufficient and that the use of visual materials such as videos and photos is necessary to inform patients (22).

A previous study discussed the effects of several methods applied to inform patients, such as plain texts, animated videos, audio-video slideshows, cartoons, and narration. The knowledge levels of the participants were measured after they received information using these methods. As a result, the study reported that the knowledge levels of the patients increased with the use of audio and video animations and audio slideshows (23). In another study that used verbal presentations, brochures, and computer-aided multimedia methods on the informed

\begin{tabular}{|l|l|l|l|}
\hline \multicolumn{2}{|l|}{ Table 1. Demographic features of the patients } & Minimum-maximum & Average \pm SD \\
\hline \multicolumn{2}{|l|}{ Age (years) } & $26-62$ & $48.30 \pm 10.96$ \\
\hline \multirow{3}{*}{ Gender } & Female & $\mathrm{n}$ & $\%$ \\
\hline \multirow{4}{*}{ Education } & Male & 35 & 83.3 \\
\hline & Literate & 7 & 16.7 \\
\cline { 2 - 4 } & Primary school & 10 & 23.8 \\
\cline { 2 - 4 } & Secondary school & 12 & 28.6 \\
\cline { 2 - 4 } & High school & 7 & 16.7 \\
\cline { 2 - 4 } & University & 5 & 11.9 \\
\hline SD: Standard deviation & & 8 & 19.0 \\
\hline
\end{tabular}

Table 2. Changes in the information and satisfaction levels before and after showing the animation video

\begin{tabular}{|c|c|c|c|c|c|}
\hline & & $\begin{array}{l}\text { Verbal-written } \\
\text { consent }\end{array}$ & $\begin{array}{l}\text { Consent with } \\
\text { animation }\end{array}$ & $\begin{array}{l}\text { Percentage of the } \\
\text { change }\end{array}$ & ap \\
\hline Knowledge on the disease findings & Average $\pm S D$ & $2.60 \pm 0.59$ & $4.81 \pm 0.71$ & $92.66 \pm 43.09$ & $0.001 * *$ \\
\hline \multirow{2}{*}{$\begin{array}{l}\text { Knowledge on the planned surgery } \\
\text { steps }\end{array}$} & Average $\pm S D$ & $2.52 \pm 0.74$ & $5.21 \pm 0.78$ & \multirow{2}{*}{$117.74 \pm 51.91$} & \multirow{2}{*}{$0.001 * *$} \\
\hline & Min-max (median) & $2-5(2)$ & $2-6(5)$ & & \\
\hline \multirow{2}{*}{ Knowledge on the complications } & Average \pm SD & $2.67 \pm 0.53$ & $3.55 \pm 0.67$ & \multirow{2}{*}{$37.30 \pm 33.90$} & \multirow{2}{*}{$0.001^{* *}$} \\
\hline & Min-max (median) & $2-4(3)$ & $3-5(3)$ & & \\
\hline \multirow{2}{*}{ Satisfaction level } & Average \pm SD & $4.83 \pm 0.76$ & $5.91 \pm 0.37$ & \multirow{2}{*}{$24.88 \pm 19.77$} & \multirow{2}{*}{$0.001^{* * *}$} \\
\hline & Min-max (median) & $4-6(5)$ & $4-6(6)$ & & \\
\hline
\end{tabular}


consent process, the status of remembering the information was measured by asking patients on the surgery day and 6 weeks after the surgery. As a result, $88 \%$ of the patients in the verbal presentation group, $76 \%$ in the brochure group, and $98 \%$ in the multimedia group provided correct answers. In the evaluation performed after 6 weeks, the permanence of the information and the satisfaction with it was high in the multimedia group (24).

We believe that understanding and learning information is easier with audiovisual materials because of their interesting and stimulating nature. In the present study, significant increases were found in the knowledge levels of the patients on disease findings, planned surgery type, alternative treatment methods, and complications after the animate video was introduced.

Although the animated video provided information only on the disease findings and surgical procedures, patients expressed a better understanding of other treatment methods and complications.

In a study that examined the effects of providing visual information on the anxiety before surgery in patients with arthritis, a 4-min video that described joint lavage was shown to one patient group, whereas no video was shown to the other group. Compared with the group without the video, the group that watched the video had lower anxiety before surgery and had significantly higher tolerability of the procedure (25). Although no numerical evaluations were made on anxiety in our study, we believe that visual animations decreased the anxiety of the patients before surgery. After they have watched the animation, none of the patients declined the planned surgical treatment and a significant increase was found in the satisfaction scores of these patients. In addition, the animation method was time efficient, as the video did not exceed 2 min. Moreover, since the animations showed the 3D structure of the tissues, they provided clearer images and information than the standard video images.

\section{Study Limitations}

This study has some limitations. First, following our literature review, we did not found any visual animation applications explaining other treatment options for hallux valgus deformity and complications about distal metatarsal osteotomy; thus, we could not provide our patients with visual animations in this context. We believe that this limitation is also applicable to visual animation designers. Second, the relation of providing information through visual animation with education, gender, and age of the patients could not be examined because of the small number of patients. Third, the same group of patients received a written/verbal explanation and visual animation. We could not form a control group because of the inadequacy of cases. Fourth, although the interval between applications was nearly 1 month, recall bias is still possible. Finally, we found it inappropriate to inform the patients only with visual animations, which is outside the standard application, in medicolegal terms. These limitations might be addressed in studies with larger patient groups.

\section{CONCLUSION}

The results of this study suggest that obtaining informed consent is not only a simple step but an important process in patient-doctor communication. This process must be managed as accurately as the surgery itself. In the present technological age, nearly every doctor owns a smartphone or a smart tablet PC, and many hospitals use electronic healthcare information systems. Visual animation applications providing audiovisual data to patients and doctors may be uploaded to these smart devices and adapted to the healthcare information system easily. We believe that visual animation applications, which are easily understood, accessible, and reproducible and provide permanent and impressive audiovisual information in patientdoctor communication by avoiding difficult medical terms, must be a standard procedure for the informed consent process.

\section{Ethics}

Ethics Committee Approval: The study was approved by the Clinical Research Ethics Committee (dated: 15.01.2016, decision no: 757).

Informed Consent: Consent form was obtained.

Peer-review: Externally peer-reviewed.

Financial Disclosure: The author declared that this study received no financial support.

\section{REFERENCES}

1. Şahin N, Cansabuncu G, Çevik N, Türker O, Özkaya G, Özkan Y. A randomized comparison of the proximal crescentic osteotomy and rotational scarf osteotomy in the treatment of hallux valgus. Acta Orthop Traumatol Turc 2018;52:261-6.

2. Klugarova J, Hood V, Bath-Hextall F, Klugar M, Mareckova J, Kelnarova Z. Effectiveness of surgery for adults with hallux valgus deformity: a systematic review. JBI Database System Rev Implement Rep 2017;15:1671-710.

3. Song JH, Kang C, Hwang DS, Lee GS, Lee SB. Comparison of Radiographic and Clinical Results After Extended Distal Chevron Osteotomy With Distal Soft Tissue Release With Moderate Versus Severe Hallux Valgus. Foot Ankle Int 2019;40:297-306. 
4. Lai MC, Rikhraj IS, Woo YL, Yeo W, Ng YCS, Koo K. Clinical and Radiological Outcomes Comparing Percutaneous Chevron-Akin Osteotomies vs Open Scarf-Akin Osteotomies for Hallux Valgus. Foot Ankle Int 2018;39:311-7.

5. Lin YK, Chen CW, Lee WC, Cheng YC, Lin TY, Lin CJ, et al. Educational video-assisted versus conventional informed consent for traumarelated debridement surgery: a parallel group randomized controlled trial. BMC Med Ethics 2018;19:23.

6. Hecht PJ, Lin TJ. Hallux valgus. Med Clin North Am 2014;98:227-32.

7. Raikin SM, Miller AG, Daniel J. Recurrence of hallux valgus: a review. Foot Ankle Clin 2014;19:259-74.

8. van Groningen B, van der Steen MC, Reijman M, Bos J, Hendriks JG. Outcomes in chevron osteotomy for Hallux Valgus in a large cohort. Foot (Edinb) 2016;29:18-24.

9. Kromuszczyńska J, Kołodziej Ł, Jurewicz A. Wound healing complications in patients with and without systemic diseases following hallux valgus surgery. PLoS One 2018;13:e0197981.

10. Michalski A, Stopa M, Miśkowiak B. Use of Multimedia Technology in the Doctor-Patient Relationship for Obtaining Patient Informed Consent. Med Sci Monit 2016;22:3994-9.

11. Braddock CH 3rd, Edwards KA, Hasenberg NM, Laidley TL, Levinson W. Informed decision making in outpatient practice: time to get back to basics. JAMA 1999;282:2313-20.

12. Egekeze N, Dubin J, Williams K, Bernhardt M. The Age of Ortholnfo: A Randomized Controlled Trial Evaluating Patient Comprehension of Informed Consent. J Bone Joint Surg Am 2016;98:e81.

13. Robinson C, Bhosale A, Pillai A. Footwear modification following hallux valgus surgery: The all-or-none phenomenon. World J Methodol 2016;6:171-80

14. Ghulam AT, Kessler M, Bachmann LM, Haller U, Kessler TM. Patients' satisfaction with the preoperative informed consent procedure: a multicenter questionnaire survey in Switzerland. Mayo Clin Proc 2006;81:307-12.
15. Carmi A, Cotler M, Fluss SKG. The UNESCO Chair in Bioethics, Informed Consent. Israel: Faculty of Law, University of Haifa. 2003.

16. Wysong PR, Driver E. Patients' perceptions of nurses' skill. Crit Care Nurse 2009;29:24-37; quiz following 37.

17. Bowers N, Eisenberg E, Montbriand J, Jaskolka J, Roche-Nagle G. Using a multimedia presentation to improve patient understanding and satisfaction with informed consent for minimally invasive vascular procedures. Surgeon 2017;15:7-11.

18. Billon L, Décaudin B, Pasquier G, Lons A, Deken-Delannoy V, Germe AF, et al. Prospective assessment of patients' knowledge and informational needs and of surgeon-to-patient information transfer before and after knee or hip arthroplasty. Orthop Traumatol Surg Res 2017;103:1161-7.

19. Bernstein J, Kupperman E, Kandel LA, Ahn J. Shared Decision Making, Fast and Slow: Implications for Informed Consent, Resource Utilization, and Patient Satisfaction in Orthopaedic Surgery. J Am Acad Orthop Surg 2016;24:495-502

20. Slover J, Shue J, Koenig K. Shared decision-making in orthopaedic surgery. Clin Orthop Relat Res 2012;470:1046-53.

21. Abu Al-Rub Z, Hussaini M, Gerrand $\mathrm{CH}$. What do patients know about their joint replacement implants? Scott Med J 2014;59:158-61.

22. Kurt E, Ucar M, Atac A. Quality of an Informed Consent Prior to a Surgical Intervention? Experience of a Teaching Hospital. Pak J Med Sci 2016;32:206-10.

23. Kraft SA, Constantine M, Magnus D, Porter KM, Lee SS, Green M, et al. A randomized study of multimedia informational aids for research on medical practices: Implications for informed consent. Clin Trials 2017; 14:94-102.

24. Cornoiu A, Beischer AD, Donnan L, Graves S, de Steiger R. Multimedia patient education to assist the informed consent process for knee arthroscopy. ANZ J Surg 2011;81:176-80.

25. Ayral X, Gicquere C, Duhalde A, Boucheny D, Dougados M. Effects of video information on preoperative anxiety level and tolerability of joint lavage in knee osteoarthritis. Arthritis Rheum 2002;47:380-2. 